\title{
Fish-Borne Zoonotic Trematodes in Cultured and Wild-Caught Freshwater Fish from the Red River Delta, Vietnam
}

\author{
Van Thi Phan,, ${ }^{1,2}$ Annette Kjær Ersbøll, ${ }^{2}$ Te Quang Bui, \\ Hang Thi Nguyen, Darwin Murrell, ${ }^{3}$ and Anders Dalsgaard ${ }^{3}$
}

\begin{abstract}
Nam Dinh province in Red River Delta, Vietnam, is an endemic area for the human liver fluke Clonorchis sinensis, but little is known about its occurrence in the fish intermediate host in this region. A cross-sectional study was carried out to identify fish-borne zoonotic trematodes (FZT) species diversity and to estimate the prevalence and infection densities of FZT in three major types of fish: cultured species and self-recruiting species from family ponds and wild-caught species from irrigation canals in Nam Dinh province. A total of 714 wild-caught fish from canals and 829 fish from family ponds were examined for FZT infection. Only a single fish from a pond was infected with $\mathrm{Cl}$. sinensis. The intestinal fluke Haplorchis pumilio was very common and found in more than $50 \%$ of fish irrespective of origin. Four other intestinal FZT species were found at low prevalence $(<4.0 \%)$ except Procerovum varium, which was found in $14.4 \%$ of wild-caught fish. There was no significant difference $(p>0.05)$ in FZT prevalence in cultured fish $(64.3 \%)$ compared with wild-caught fish $(68.9 \%)$, nor between cultured fish species $(65.1 \%)$ and self-recruiting species obtained from ponds $(58.1 \%)$. The prevalence of FZT in silver carp (Hypophthalmichthys molitrix) $(82.7 \%)$, grass carp (Ctenopharyngodon idellus) $(76.9 \%)$, and mrigal (Cirrhinus mrigala) $(63.8 \%)$ was significantly higher than that in rohu (Labeo rohita) $(49.1 \%)(p<0.001)$. The density of FZT metacercariae in fish from canals $(0.56$ metacercariae $/ g)$ was significantly higher $(p<0.001)$ than that in fish from ponds $(0.03$ metacercariae $/ \mathrm{g})$. The frequent occurrence of intestinal flukes in all fish types indicates that wild-caught and cultured fish are equally at risk of infection with FZT, particularly in species commonly used in Nam Dinh to prepare raw fish dishes. These results underscore the need for greater awareness of the risk from raw fish dishes among public health agencies and consumers.
\end{abstract}

Key Words: Aquaculture-Epidemiology—Fish—Trematodes—Vietnam-Zoonoses.

\section{Introduction}

$\mathbf{F}$ ISH-BORNE ZOONOTIC TREMATODES (FZT) are well-known causes of liver and intestinal trematode (fluke) diseases in humans (Chai et al. 2005). The strong cultural preferences in many countries, particularly in Asia, for eating raw or insufficiently cooked infected fish are believed to be the greatest risk factor for human infection (WHO 2004, Chai et al. 2005). It has been estimated that about 680 million people worldwide are at risk of infection apart from more than 20 million humans already infected with liver flukes (Clonorchis sinensis and Opisthorchis spp.) (Keiser and Utzinger 2005). In Vietnam, WHO (2004) estimates that approximately 1 million people are infected with $\mathrm{Cl}$. sinensis and Opisthorchis viverrini. De et al. (2003) reported that the liver fluke species are geographically separated in Vietnam, with $\mathrm{Cl}$. sinensis endemic in Northern Vietnam and O. viverrini confined to Southern Vietnam. The prevalence of humans infected with intestinal flukes, in Vietnam and elsewhere, is not as well documented (Chai et al. 2005).

A recent study involving the recovery adult of FZT from human and animals revealed a high prevalence in humans

\footnotetext{
${ }^{1}$ Centre for Environment and Disease Monitoring in Aquaculture, Research Institute for Aquaculture No.1, Tu Son, Vietnam.

${ }^{2}$ Section of Veterinary Epidemiology, Department of Large Animal Sciences, Faculty of Life Sciences, University of Copenhagen, Copenhagen, Denmark.

${ }^{3}$ Department of Veterinary Disease Biology, Faculty of Life Sciences, University of Copenhagen, Copenhagen, Denmark.
} 
$(64.9 \%)$, cats $(70.2 \%)$, and dogs $(56.9 \%)$ in Nam Dinh province, located in the Red River Delta (Dung et al. 2007, Anh et al. 2009). However, there has been only limited attention to FZT in fish in Vietnam, especially in Red River Delta, which is known to be endemic for human FZT infection, because they were not considered harmful to fish and seriously affecting aquaculture production. The fishery sector is very important in Vietnam and is a major protein resource for domestic consumption. It was estimated that fish consumption per capita in South East Asian countries, including Vietnam, was $28 \mathrm{~kg}$ in 2005 (FAO 2008). Although cultured fish species are of main economic and food security importance, wild-caught fish from canals and self-recruiting species (SRS; these are fish that have been introduced from water bodies into the cultured ponds) from ponds in rural areas of Northern Vietnam are also important for low-income farmers (Little et al. 2004).

The lack of in-depth knowledge on FZT epidemiology in fish restricts efforts for improving the management practices and food safety in aquaculture production. To help fill this need, the cross-sectional study reported here was carried out during 2006 in Nam Dinh province in the Red River Delta as part of a longitudinal risk assessment of FZT infection in fish. Here the local people have a long tradition of eating raw freshwater fish. The objectives of the study were to identify FZT species diversity and to estimate the prevalence and infection densities of FZT in fish species from irrigation canals (wild-caught) and from family ponds (cultured species and SRS).

\section{Materials and Methods}

\section{Study area}

The study was conducted in two communes in Nghia Hung district, Nam Dinh province. The province has a total area of $1651 \mathrm{~km}^{2}$ and 1,974,300 habitants (2006 census) with six rivers and traversed with many canals. Freshwater fish production in the province consists of fish cultured, SRS in ponds, and wild-caught fish from irrigation canals. The term "wildcaught fish" means that fish were collected outside the aquaculture system and such fish are generally small in size and, therefore, are marketed in mixed species batches. In the Nghia Lac and Nghia Phu communes aquaculture is practiced mainly in household ponds stocked with multiple fish species and raised in a continuous production cycle. The major fish species cultured are grass carp (Ctenopharyngodon idellus), silver carp (Hypophthalmichthys molitrix), common carp (Cyprinus carpio), rohu (Labeo rohita), and mirgal (Cirrhinus mrigala). In the studied communes, most of households locate the toilets outside the main house, and some households had it near the pond. Free-roaming domesticated animals seen in this area were dogs, cats, chicken, and ducks.

\section{Selection of households, canals, and collection of fish}

The lists of households in Nghia Lac and Nghia Phu communes were obtained and used for the selection of households for the study. Households with no ponds and households that participated in a previous FZT prevalence study in humans were excluded (Dung et al. 2007). A total of 75 households were randomly selected; if the household had more than one pond, one pond was randomly selected. Samples of fish in the ponds were collected using a cast net, which was thrown in each of the four corners and in the middle of each pond. All fish caught from the five throws were mixed and 10 fish were randomly selected for examination. However, at some ponds less than 10 fish were obtained. In total, 747 fish were collected from aquaculture ponds belonging to 16 fish species of which 8 were SRS. Wild-caught fish were sampled from the main irrigation canals of two communes. Due to difficulties using casting net in canals, lift nets were sometimes used. In each canal, 10-12 fish were sampled from 30 different locations. A total of 714 wild-caught fish representing 19 fish species were collected and examined.

\section{Examination for FZT metacercariae}

Collected fish were preserved on ice and transported within $12 \mathrm{~h}$ to the parasitology laboratory of the Centre for Environment and Disease Monitoring in Aquaculture located in Bac Ninh province, where they were processed for recovery of FZT metacercariae by a pepsin digestion method. In the laboratory, fish were kept in a refrigerator at $4{ }^{\circ} \mathrm{C}$ for no more than 5 days before being processed. The length and weight of each fish was recorded before being processed and digested in $1 \%$ pepsin for the release of metacercariae following the procedure described in Annex 6 of WHO (1995) and modified as described by Chi et al. (2008). Small fish (less than $200 \mathrm{~g}$ in weight) were ground and digested whole. For larger fish $(>200 \mathrm{~g})$, the whole fish was ground, and a $50 \mathrm{~g}$ subsample was obtained and digested for recovery of metacercariae. Solutions of $0.85 \%$ saline were used for the washing and settling of the digested sediment. When the supernatant was clear, the sediment was examined under a stereo microscope. Metacercariae were separated, counted, and mounted on a glass slide under a cover slip and examined with both stereo $(\times 4)$ and compound $(\times 100)$ microscopes. In some cases to assist their morphological identification, the encysted metacercariae were excysted by pressing on the cover slip or by placing them in trypsin digestion fluid $(0.4 \%$ sodium hydrogen carbonate, $1.0 \%$ trypsin, and $0.85 \% \mathrm{NaCl}$ ) (Komiya 1965) until they emerged from the cyst. Identification of the metacercariae was according to the morphological features described in detail by Yamaguti (1971), Velasquez (1973), Pearson and Ow-Yang (1982), Scholtz et al. (1991), and Kaewkes (2003) for metacercariae. To validate morphological metacercariae of each FZT species found in fish, in some instances, mice were inoculated with the metacercariae for adult worm recovery to facilitate identification following the published procedures (Kay et al. 2009).

\section{Study design and statistical analysis}

The study was designed as a cross-sectional study. Data collected in the field and from laboratory analysis were recorded in an Excel spreadsheet (Microsoft Office Excel, 2003) and then imported into the Statistical Analysis System (SAS, version 9.1, Cary, NC) for statistical analysis. It was not possible to identify the species of 24 fish, and therefore they were categorized as "other species." Initially, descriptive analysis of the prevalence of FZT was done for fish in ponds and canals. There was a broad range of fish species caught from canals and ponds. Therefore, fish species with less than 50 individuals were excluded from the analysis of differences in FZT prevalence between fish from different origins. When comparing the prevalence of FZT in wild-caught fish in canals and 
Table 1. Occurrence of Fish-Borne Zoonotic Trematode Metacercariae Stratified by Fish-Borne Zoonotic Trematode Species in Fish from Ponds and Canals

\begin{tabular}{lccc}
\hline & & FZT prevalence \% (no. infected/no. examined) \\
\cline { 2 - 4 } FZT species & Fish from ponds & Wild-caught fish from canals & Total \\
\hline Haplorchis pumilio & $62.1(515 / 829)$ & $57.0(407 / 714)$ & $59.8(922 / 1543)$ \\
Haplorchis taichui & $0(0 / 829)$ & $0.1(1 / 714)$ & $0.1(1 / 1543)$ \\
Haplorchis yokogawai & $0.1(1 / 829)$ & $0.1(1 / 714)$ & $0.1(2 / 1543)$ \\
Centrocestus formosanus & $2.2(18 / 829)$ & $3.5(25 / 714)$ & $2.8(43 / 1543)$ \\
Procerovum varium & $0.1(1 / 829)$ & $14.4(103 / 714)$ & $6.7(104 / 1543)$ \\
Clonorchis sinensis & $0.1(1 / 829)$ & $0(0 / 714)$ & $0.1(1 / 1543)$ \\
\hline
\end{tabular}

FZT, fish-borne zoonotic trematodes.

SRS fish in ponds, all common carp and mrigal caught in canals were excluded because these two species are exclusively cultured species and were assumed to be escapes from aquaculture ponds. Due to a skewed distribution of density of metacercariae (number of metacercariae/g) descriptive analysis was performed by means of median, $\mathrm{Q}_{1}(25 \%$ percentile), $\mathrm{Q}_{3}$ (75\% percentile), and minimum and maximum values.

Logistic analysis was used to evaluate prevalence differences of FZT between origin (canal and pond), location of commune (Nghia Lac and Nghia Phu), and noncultured fish species (wild-caught species and SRS). Study unit was the individual fish collected from one pond in each household in each commune. Therefore, a multilevel data structure was used with household randomly sampled within each of the two commune and fish were randomly sampled within each household (i.e., pond). Household nested within a commune was included as a random effect when using logistic analysis to evaluate differences of FZT prevalence between cultured species and SRS within ponds. Odds ratios were calculated only for significant factors.

An analysis of variance of metacercariae density was performed to evaluate differences of FZT density between fish from canals and ponds, as the metacercariae density is a continuous variable. Due to a skewed distribution of metacercariae density, a rank transformation of densities was applied.

A $p$-value $<0.05$ was considered significant.

\section{Results}

\section{The prevalenc of FZT species in fish}

Fish from canals harbored a total of five species of zoonotic intestinal trematodes (Heterophyidae), namely, Haplorchis pumilio, Haplorchis taichui, Haplorchis yokogawai, Centrocestus formosanus, and Procerovum varium, whereas fish from ponds

Table 2. Occurrence of Fish-Borne Zoonotic Trematode Metacercariae in Different Fish Species from Ponds and Canals

\begin{tabular}{|c|c|c|c|}
\hline \multirow[b]{2}{*}{ Fish species examined } & \multicolumn{3}{|c|}{ FZT prevalence \% (no. infected/no. examined) } \\
\hline & Fish from ponds & Fish from canals & Total \\
\hline Climbing perch (Anabas testudineus) & $100(3 / 3)$ & $67.7(44 / 65)$ & $69.1(47 / 68)$ \\
\hline Black goby (Eleotris melanosoma) & - & $36.7(18 / 49)$ & $36.7(18 / 49)$ \\
\hline White goby (Glossogobius aureus) & - & $47.5(28 / 59)$ & $47.5(28 / 59)$ \\
\hline Cutler fish (Hemiculter leucisculus) & $0(0 / 2)$ & $66.7(2 / 3)$ & $40.0(2 / 5)$ \\
\hline Catfish (Clarias batrachus) & $0(0 / 1)$ & $83.3(5 / 6)$ & $71.4(5 / 7)$ \\
\hline Common carp (Cyprinus carpio) & $54.3(19 / 35)$ & $84.0(21 / 25)$ & $66.7(40 / 60)$ \\
\hline Crucian carp (Carrasius auratus) & $54.3(19 / 35)$ & $74.0(176 / 238)$ & $74.4(195 / 273)$ \\
\hline Goby (Prionobutis koilomatodon) & - & $7.7(1 / 13)$ & $7.7(1 / 13)$ \\
\hline Grass carp (Ctenopharyngodon idellus) & $76.9(69 / 87)$ & - & $76.9(69 / 87)$ \\
\hline Grey mullet (Mugil cephalus) & - & $84.2(16 / 19)$ & $84.2(16 / 19)$ \\
\hline Rohu (Labeo rohita) & $49.1(144 / 293)$ & - & $49.1(144 / 293)$ \\
\hline Stream fish (Rasborinus lineatus) & - & $82.8(82 / 99)$ & $82.83(82 / 99)$ \\
\hline Mrigal (Cirrhinus mrigala) & $63.8(67 / 105)$ & $60.0(9 / 15)$ & $63.33(76 / 120)$ \\
\hline Mud carp (Cirrhinus molitorella) & $50.0(2 / 4)$ & $100(1 / 1)$ & $60.00(3 / 5)$ \\
\hline Pacu (Piaractus brachypomum) & $40.0(2 / 5)$ & - & $40(2 / 5)$ \\
\hline Red eye carp (Squaliobarbus curriculus) & $61.7(29 / 47)$ & $100(1 / 1)$ & $62.5(30 / 48)$ \\
\hline Sail fish (Istiophorus sp.) & - & $65.5(38 / 58)$ & $65.5(38 / 58)$ \\
\hline Silver carp (Hypophthalmichthys molitrix) & $82.7(186 / 225)$ & - & $82.7(186 / 225)$ \\
\hline Snake head fish (Channa orientalis) & $100(1 / 1)$ & $100(4 / 4)$ & $100(5 / 5)$ \\
\hline Bronze featherback (Notopterus notopterus) & -1 & $100(2 / 2)$ & $100(2 / 2)$ \\
\hline Tilapia (Oreochromis niloticus) & $12.5(1 / 8)$ & - & $12.5(1 / 8)$ \\
\hline Loach (Anguilla marmorata) & - & $85.2(23 / 27)$ & $85.2(23 / 27)$ \\
\hline Mai trang river (Rasborionus hautus) & - & $100(6 / 6)$ & $100(6 / 6)$ \\
\hline Others (not identified) & - & $62.5(15 / 24)$ & $62.5(15 / 24)$ \\
\hline
\end{tabular}


Table 3. Prevalence of Fish-Borne Zoonotic Trematodes in Fish Stratified by Commune and Different Groups of Fish Species

\begin{tabular}{lll}
\hline Variable & \multicolumn{1}{c}{ Level } & $\begin{array}{c}\text { FZT prevalence \% } \\
\text { (no. infected) } \\
\text { no. examined) }\end{array}$ \\
\hline Commune & Nghia Lac & $72.6(587 / 809)$ \\
Fish species in pond & Nghia Phu & $59.7(383 / 734)$ \\
Not cultured species & Cultured species & $65.1(54 / 93)$ \\
& SRS & $58.1(479 / 736)$ \\
& Wild-caught species & $68.6(54 / 93)$ \\
\end{tabular}

SRS, self-recruiting species.

were infected with four species, namely, H. pumilio, H. yokogawai, Ce. formosanus, and P. varium (Table 1). The liver fluke, $\mathrm{Cl}$. sinensis, was only recovered from a single pond fish. $\mathrm{H}$. pumilio was by far the most commonly found in $62.1 \%$ and $57.0 \%$ of cultured fish and wild-caught fish from canals, respectively (Table 1). Other FZT species were found at low prevalence $(<4.0 \%)$ except $P$. varium, which was found in $14.4 \%$ of wild-caught fish. All fish species sampled in the study were infected by FZT at different prevalence. The prevalence of FZT metacercariae in different fish species from ponds (cultured species and SRS) and canals (wild-caught species) fish is shown in Table 2. The prevalence of FZT in fish stratified by commune and different groups of fish ranged from $58.1 \%$ to $72.6 \%$ (Table 3 ).

\section{Comparison of FZT prevalence between cultured and wild-caught fish from the two communes}

The prevalence of FZT in fish from Nghia Lac commune was significantly higher $(p<0.001)$ than that in fish from Nghia Phu commune (Table 4 ). There was no significant difference in FZT prevalence between wild-caught fish from canals and ponds from both communes. Among cultured species in ponds, the prevalence of FZT in silver carp, grass carp, and mrigal was significantly higher than that in rohu $(p<0.0001)$. The prevalence of FZT in cultured fish was not significantly higher than that in the SRS species. However, the prevalence of FZT in SRS obtained in ponds was significantly lower than that in wild-caught fish $(p<0.05)$.

\section{Density of FZT metacercariae in wild-caught and cultured fish}

The density of FZT metacercariae in wild-caught fish from canals was significantly greater $(p<0.001)$ than that in fish from ponds (Table 5) (0.56 metacercariae/g compared with 0.03 metacercariae $/ g$ ). There was no significant difference between density of FZT in fish from Nghia Lac and Nghia Phu communes (Table 5).

\section{Discussion}

The diversity of FZT species recovered from cultured fish species, SRS and wild-caught fish, in this study is similar to the diversity of adult intestinal flukes recovered recently from humans and domestic animals in the same study area of

Table 4. Estimated Effects of (1) Commune and Fish Origin, (2) Type of Fish Species in Ponds, (3) Noncultured Species, and (4) Main Cultured Species in Ponds

\begin{tabular}{|c|c|c|c|c|c|c|c|c|}
\hline Analyses & Variable & Level & Estimate & $S E$ & $\mathrm{p}$ & OR & 95 & CI \\
\hline \multirow[t]{5}{*}{ Commune and fish origin } & Intercept & & 0.308 & 0.089 & $<0.001$ & & & \\
\hline & Commune & Nghia lac & 0.575 & 0.109 & $<0.0001$ & 1.79 & 1.44 & 2.21 \\
\hline & & Nghia phu & 0 & - & - & 1 & - & - \\
\hline & Fish origin & Canal & 0.191 & 0.110 & 0.082 & & & \\
\hline & & Pond & 0 & - & - & - & - & - \\
\hline \multirow{5}{*}{$\begin{array}{l}\text { Type of fish species } \\
\text { in ponds }\end{array}$} & Intercept & & 0.577 & 0.160 & $<0.001$ & - & - & - \\
\hline & Commune & Nghia lac & 0.166 & 0.228 & 0.47 & & & \\
\hline & & Nghia phu & 0 & - & & & & \\
\hline & Type of fish species & SRS species & -0.309 & 0.250 & 0.22 & & & \\
\hline & & Cultured species & 0 & - & - & - & - & 一 \\
\hline \multirow[t]{5}{*}{ Not cultured species } & Intercept & & 0.233 & 0.112 & 0.037 & & & \\
\hline & Commune & Nghia lac & 1.112 & 0.163 & $<0.001$ & 3.04 & 2.21 & 4.18 \\
\hline & & Nghia phu & 0 & - & & 1 & & \\
\hline & Type of fish species & SRS species in pond & -0.711 & 0.238 & 0.003 & 0.49 & 0.31 & 0.78 \\
\hline & & $\begin{array}{l}\text { Wild-caught species } \\
\text { in canal }\end{array}$ & 0 & - & - & 1 & - & - \\
\hline \multirow[t]{7}{*}{ Main cultured species } & Intercept & & -0.194 & 0.221 & 0.38 & & & \\
\hline & Commune & Nghia lac & 0.171 & 0.286 & 0.55 & & & \\
\hline & & Nghia phu & 0 & - & & & & \\
\hline & Fish species & Grass carp & $1.714^{\mathrm{a}}$ & 0.336 & $<0.001$ & 5.55 & 2.87 & 10.74 \\
\hline & & Mrigal & $0.636^{\mathrm{b}}$ & 0.289 & & 1.89 & 1.07 & 3.33 \\
\hline & & Silver carp & $1.911^{\mathrm{a}}$ & 0.261 & & 6.76 & 4.05 & 11.29 \\
\hline & & Rohu & $0^{c}$ & - & & 1 & & \\
\hline
\end{tabular}

For each of the four models, the parameter estimates, standard error (SE), overall $p$-value, odds ratio (OR), and 95\% confidence intervals (CI) are given.

OR and the corresponding 95\% CI are only given for significant effects.

$\mathrm{a}, \mathrm{b}, \mathrm{c}$ Indicates significant differences. 
Table 5. Density of Fish-Borne Zoonotic Trematode Metacercariae in Cultured and Wild-Caught Fish (Number of Metacercariae/g) from Nghia Lac and Nghia Phu Communes

\begin{tabular}{|c|c|c|c|c|c|c|c|c|c|c|c|c|}
\hline \multirow[b]{2}{*}{ Origin } & \multicolumn{6}{|c|}{ Fish from ponds } & \multicolumn{6}{|c|}{ Wild-caught fish from canals } \\
\hline & $\mathrm{n}$ & Min & $Q_{1}$ & $M D$ & $Q_{3}$ & $\operatorname{Max}$ & $\mathrm{n}$ & Min & $Q_{1}$ & $M D$ & $Q_{3}$ & $\operatorname{Max}$ \\
\hline Overall & 747 & 0 & 0 & 0.03 & 0.24 & 171.00 & 704 & 0 & 0 & 0.56 & 4.16 & 422.38 \\
\hline Nghia lac & 370 & 0 & 0 & 0.03 & 0.24 & 34.35 & 388 & 0 & 0.06 & 1.64 & 8.73 & 422.38 \\
\hline Nghia phu & 377 & 0 & 0 & 0.03 & 0.26 & 171.00 & 316 & 0 & 0 & 0 & 1.04 & 180.72 \\
\hline
\end{tabular}

$\mathrm{n}$, number of fish; MD, median; min, minimum values; max, maximum values; $\mathrm{Q}_{1}, 25 \%$ percentiles; $\mathrm{Q}_{3}, 75 \%$ percentiles.

Northern Vietnam (Dung et al. 2007, Anh et al. 2009). Based on the results obtained in present and other studies (Thien et al. 2007, Chi et al. 2008) the most frequent intestinal zoonotic flukes in fish, domestic animals, and humans throughout Vietnam are members of the Haplochorinae, predominantly $H$. pumilio. The wide distribution of these intestinal fluke species is probably related to their broad host ranges, which include many mammals and fish-eating birds, a condition that increases opportunities for successful life cycle completions. The ubiquity of the snail vector Melanoides tuberculata in Vietnam may also be an important factor favoring the distribution of these intestinal flukes. Comprehensive studies on the snail, fish, and reservoir host ranges for this trematode in Southeast Asia are, however, as yet not comprehensive enough to permit any conclusions on this issue.

Two species of FZT, Stellantchasmus falcatus and Cl. sinensis, recovered from humans living in Nghia Phu and Nghia Lac communes (Dung et al. 2007) were not found in fish from these communes. This suggests that humans are likely to acquire these FZT species from wild-caught or cultured fish imported from other areas. An evaluation of the influence of the human eating behaviors, including fish species preferences and their sources, may reveal risk factors that could explain these differences in FZT prevalence.

The prevalence of FZT in fish from ponds (64.3\%) was higher than that reported for similar aquacultures system in northern, central, and southern provinces (Chi et al. 2008, Thien et al. 2007). For some of fish species, the sample size was very small. Therefore, the prevalence was estimated with high uncertainty for these species. Species with small sample size were excluded in statistic analysis. The density of FZT metacercariae from fish in Nghia Lac and Nghia Phu communes is also much higher than that reported from other areas in Vietnam (Chi et al. 2008, Thien et al. 2007, Thu et al. 2007). Although this may be related to regional differences such as fish farming practices, snail and reservoir host distributions, among others, our findings demonstrate for the first time that FZT-infected wild-caught fish from irrigation canals in Vietnam represent a significant food safety risk. The significant difference in FZT prevalence between wild-caught fish from canals in Nghia Lac (68.9\%) and from Nghia Phu (80.2\%) communes may be related to the fact that households in Nghia Phu were densely located at the edge of the canal, enhancing the opportunity for fluke eggs in waste water from human activities and animal cages to be directly discharged to the canal. A high FZT egg contamination of water bodies has been shown to be an important aspect of FZT epidemiology (Naegel 1990, WHO 2006).

The high FZT prevalence in cultured and wild-caught carps, especially silver carp, grass carp, mrigal, and rohu, should increase awareness of public health agencies and of consumers, because these species are frequently used for preparing raw fish dishes. Therefore, people should not eat raw fish dishes unless the fish were first treated with some procedure that kills metacercariae (WHO 2004). Further, the wide range and high prevalence of FZT-infected wild-caught and SRS fish species are an often overlooked problem because the fish are often used uncooked in animal feed preparations, presenting a risk to potential reservoir hosts.

In our study, the density of FZT in wild-caught fish from canals was 10 times higher than that in fish from ponds. The higher FZT prevalence and density in wild-caught fish species compared with similar species (SRS) from ponds may reflect the longer exposure time to cercariae of wild-caught fish. Wild-caught fish in the canals are not captured regularly and consequently probably have much longer life spans than SRS because SRS fish are normally harvested after several months and are seldom subject to exposure periods comparable to wild-caught fish. Further studies on the effect of different risk factors for differences in FZT density in canal and pond fish are necessary for confirmation.

The high prevalence of FZT found in cultured and wildcaught species often used to prepare raw fish dishes represents a food safety risk and calls for better aquaculture management practices to control FZT, whereas control of FZT in wild-caught fish will be difficult.

\section{Acknowledgments}

The authors would like to thank the staff of the Centre for Environment and Disease Monitoring in Aquaculture, Research Institute for Aquaculture No. 1, for their support in the field and laboratory analyses. The authors appreciate farmers who participated in this study. Special thanks to Nguyen Viet Khue for his arrangement with fish sampling and Vo Van Binh for help in identifying the species of the collected fish. The Danish International Development Assistance (Danida) is gratefully acknowledged for its financial support to this study through the project titled "Fish Borne Zoonotic Parasite in Vietnam" (http://fibozopa.ria1.org).

\section{Disclosure Statement}

Each author hereby confirms that there is no competing financial interests exist in connection with this article.

\section{References}

Anh, NTL, Phuong, NT, Johansen, MV, et al. Prevalence and risks for fishborne zoonotic trematode infections in domestic animals in a highly endemic area of North Vietnam. Acta Trop 2009; 112:198-203. 
Chai, JY, Murrell, KD, Lymbery, AJ. Fish borne parasitic zoonoses: status and issues. Int J Parasitol 2005; 35:1233-1254.

Chi, TTK, Dalsgaard, A, Turnbull, JF, Pham, AT, et al. Prevalence of zoonotic trematodes in fish from Vietnamese fishfarming community. J Parasitol 2008; 94:423-428.

De, NV, Murrell, KD, Cong, LD, Cam, PD, et al. The food-borne trematode zoonoses of Vietnam. Southeast Asian J Trop Med Public Health 2003; 34(Suppl):12-35.

Dung, DT, De, NV, Waikagul, J, Dalsgaard, A, et al. Fishborne zoonotic intestinal trematodes, Vietnam. Emerg Infect Dis 2007; 13:1828-1833.

[FAO] Food and Agriculture Organization of the United Nation. The State of World Fisheries and Aquaculture. Electronic Publishing Policy and Support Branch, Communication Division, FAO Rome, Italy; 2008:196.

Kaewkes, S. Taxonomy and biology of liver flukes. Acta Trop 2003; 88:177-186.

Kay, H, Murrell, KD, Kornerup, A, Madsen, H, et al. Optimization of an experimental model for the recovery of adult Haplorchis pumilio. J Parasitol 2009.

Keiser, J, Utzinger, J. Emerging foodborne trematodiasis. Emerg Infect Dis 2005; 11:1507-1514.

Komiya, M. Metacercariae in Japan and Adjacent Territories: Progress of Medical Parasitology in Japan, vol. II. Tokyo: Meguro Parasitological Museum, 1965:328.

Little, D, Lorenzen, K, Amilhat, E, Morales, E, et al. SelfRecruiting Species in Aquaculture-Their Role in Rural Livelihoods. DFID Fisheries Management Science Programme, Final Technical Report, project R7917. Institute of Aquaculture, Imperial College London and Asian Institute of Technology, 2004:73.

[MOFI] Ministry of Fisheries. Annual report. 2007, Hanoi, Vietnam.

Naegel, LCA. A review of the public health problems associated with the integration of animal husbandry and aquaculture, with emphasis on Southeast Asia. Biol Wastes 1990; 31: 69-83.

Pearson, JC, Ow-Yang, CK. New species of Haplorchis from Southeast Asia, together with keys to the Haplorchis-group of heterophyid trematodes of the region. Southeast Asian J Trop Med Public Health 1982; 13:35-60.

Scholtz, T, Ditrich, O, Giboda, M. Differential diagnosis of Opisthorchid and Heterophyid metacercariae (Trematoda) infecting flesh of cyprinid fish from Nam Ngum Dam Lake in Lao PDR. Southeast Asian J Trop Med Public Health 1991; 22:171173.

Thien, PC, Dalsgaard, A, Thanh, BN, Olsen, A. Prevalence of fishborne zoonotic parasites in important aquaculture fish species in the Mekong Delta, Vietnam. Parasitol Res 2007; 101:1277-1284.

Thu, ND, Loan, LTT, Dalsgaard, A, Murrell, KD. Survey for zoonotic liver and intestinal trematode metacercariae in aquaculture and wild fish in An Giang Province, Vietnam. Korean J Parasitol 2007; 45:45-54.

Velasquez, C. Observations on some Heterophyidae (Trematoda:Digenea) encysted in Philippine fishes. J Parasitol 1973; 59:77-84.

[WHO] World Health Organization. Control of Foodborne Trematode Infections. Report of a WHO Study Group. WHO Tech Rep Ser, Annex 6, Geneva, 1995.

[WHO] World Health Organization. Report of a Joint WHO/FAO Workshop on Food-Borne Trematode Infections in Asia, Hanoi, Vietnam 26-28 November, 2002. WPRO 2004:1-58.

[WHO] World Health Organization. Guidelines for the Safe Use of Wastewater, Excreta and Greywater, vol. III. Wastewater and Excreta Use in Aquaculture. Geneva, 2006.

Yamaguti, S. Synopsis of Digenetic Trematodes of Vertebrates, vols. I and II. Tokyo, Japan: Keigaku Publishing Company, 1971.

Address correspondence to: Van Thi Phan

Centre for Environment and Disease Monitoring in Aquaculture Research Institute for Aquaculture No.1

Dinh Bang, Tu Son

Bac Ninh 84

Vietnam

E-mail: phanthivan_vn@yahoo.com or phanvan@ria1.org 